\title{
MT-AMT Resolution of Conductive Sediments Overlain by Deccan Flood Basalt (India): A Numerical Experiment
}

\author{
K. VEERASWAMY and U. RAVAL \\ National Geophysical Research Institute, Hyderabad-500 007, India
}

(Received October 3, 1988; Revised August 24, 1989)

\begin{abstract}
The presence of Mesozoic-Gondwana sediments below the cover of Deccan flood basalt, as inferred on the basis of Deep Seismic Sounding (DSS) (KAILA, 1986), needs to be complemented by other geophysical methods. In view of this and the increasing emphasis on combined seismic and electrical probing (JONES, 1987), a Magneto-Telluric (MT)-Audio Magneto-Telluric (AMT) coverage of the DSS profiles on the Deccan Traps is suggested. In order to gain a quantitative insight and aid the field campaign, a theoretical analysis of the geoelectromagnetic problem is presented here. A shallow subsurface section (up to $2-3 \mathrm{~km}$ depth) under the UjjainMahan profile, deduced from the refraction data, has been simulated. The electromagnetic response of a 2-D sedimentary inhomogeneity sandwiched between the upper basaltic layer and the granitic basement is computed using a finite element algorithm and for the plausible parametric values taken from field studies (SUbRAhmANyAm, 1987) and the literature (CLARK, 1966). Quantitative estimates of induction characteristics along the selected profile are obtained for variations in a) thicknesses and conductivities of the trap, b) conductivities of sediments, c) conductivities of the basement and d) the period of exitation. The comparison of results for the E- and B-polarization modes reveal that the latter is significantly more sensitive to the dip of a contact fault controlling the subsurface sedimentary structure under the Ujjain-Mahan section. The analysis also takes into account the influence of the sloping interfaces and topography at the surface and deeper levels.
\end{abstract}

\section{Introduction}

Within the framework of Indian geology and tectonics, the Deccan Traps, which is a vast Tertiary flood basaltic eruption, has been a major area for multidisciplinary investigations for the following reasons:

i) It is among the largest intraplate flood basaltic eruptions in the world, with an area of approximately $10^{6} \mathrm{~km}^{2}$, thickness varying between $100-2000 \mathrm{~m}$, and a volume exceeding $10^{6} \mathrm{~km}^{3}$ (DESHMUKH, 1982). Allowing for the erosion processes active since its eruption ( $\sim 65$ my ago), the original volume would have been at least twice the existing one. However, the mode of origin of this midplate volcanism remains debatable owing to various possible causes (viz. a hotspot, a propagating fracture or some other mechanism).

ii) These Cretaceous-Tertiary basalts cover a large area of the central and 
western part of the subcontinent. Therefore, characteristics of the pre-trappean basement under this large area are mostly unknown. A substantial part of it also lies on the continental margin (MAHONEY, 1988) in the Arabian Sea, which is indicative of the possible linkage of the Deccan magmatism with the breakup of the Indian subcontinent from Africa and Madagascar.

iii) At least two major lineaments or rifts, the Narmada-Son and the Godavari, pass through it, which show signs of an extensional regime. Hidden rifts have also been suggested (KRISHNA BRAHMAM and NEGI, 1973) on the basis of gravity. The Cambay graben virtually separates the central part of the Deccan trap from that in the Saurashtra peninsula on the west.

iv) Temporally, it follows the major sedimentation cycle of the Gondwana system (paleo or Mesozoic group). Delineation of sedimentary structures is of particular significance in view of their possible hydrocarbon potential.

v) Much of this magmatic activity seems to have taken place over proterozoic mobile belts consisting of the Aravallis and Satpura mountains.

vi) Recently it has attracted added attention due to its time and rate of eruption nearly coinciding with the well known K-T boundary and the postulate of (a) a very short span of eruption (0.5-1.4 ma) (COURTILlOT et al., 1986; BAKSHI, 1987) and (b) attendant faunal extinction and impact cratering (ALVAREZ, 1986; HARTNADY, 1987).

The above points obviously necessitate a more detailed and multiparametric investigation of this region. Among some of the attempts in this direction are electrical conductivity studies (SRIVASTAVA and PRASAD, 1982); a teleseismic study (IYER et al., 1986) and the DSS studies over various parts of the Deccan trap area (KAILA, 1986). The latter aim at 1) deciphering and constraining the presence of the postulated sediments through its shallow section, 2) inferring the deeper section, i.e., the crust-mantle structure below the region.

\section{Problem of LVL}

This well-known difficulty is clearly manifested here as Mesozoic sediments, possessing relatively low velocity, lie between the high velocity zones of the overlying Deccan flood basalts and the basement underneath. It is usually difficult to delineate such sandwiched low velocity layers by seismic refraction probing. Figure 1(a) depicts the typical time distance curves for a 3-layer earth model for the two cases (i) $V_{1}<V_{2}<V_{3}$ and (ii) $V_{1}>V_{2}<V_{3}$ where $V_{1}, V_{2}$ and $V_{3}$ denote the velocity of seismic waves in different layers. The transition from case (i) to (ii) reveals (Fig. 1(a)) the difficulty in delineating a low velocity layer. Another set of curves (Fig. 1(b)) is for the apparent resistivity of a 3-layer model and for the cases where $\rho_{1}<\rho_{2}<\rho_{3}$ or $\rho_{1}>\rho_{2}<\rho_{3}$ with $\rho_{1}, \rho_{2}, \rho_{3}$ being resistivities of the layers. It may be seen from Fig. 1(b) that the sandwiched conductive layer gets clearly reflected in the induction characteristics, unlike the masking seen in earlier case of seismic low velocity layer. VOzOFF (1972) has thus suggested that the MT method may be well-suited to areas covered by near surface volcanic rocks which are difficult to 

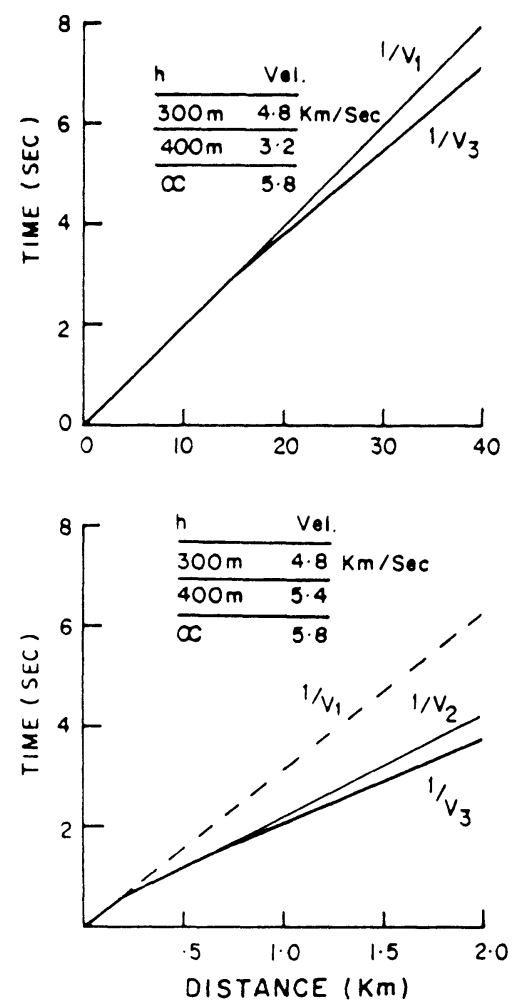

b
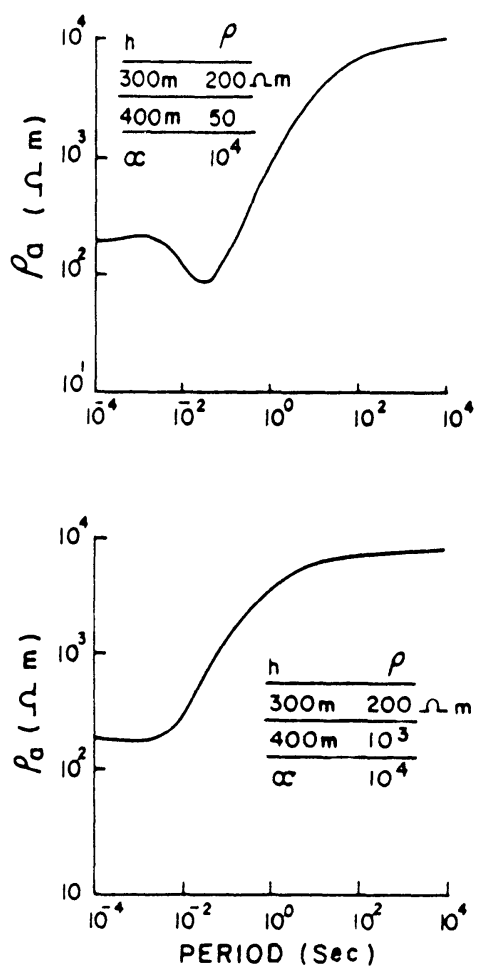

Fig. 1. (a) Time-distance curves and (b) apparent resistivity $\left(\rho_{\mathrm{a}}\right)$ versus period curves for 3-layered models with transition in the velocity (or resistivity) of the sandwiched layer.

explore by conventional seismic means. It is also being increasingly emphasized that the seismic sections derived by the reflection method need to be supplemented by other geophysical methods, in particularly Magneto-Tellurics (JONES, 1987). The power of geoelectromagnetic or MT methods is derived from the large order of change in conductivity values exhibited by earth material $\left(10\right.$ to $\left.10^{-6} \mathrm{~S} / \mathrm{m}\right)$ in comparison to relatively small contrasts found in other physical properties, including the seismic characteristics.

From the above it seems that the e.m. technique is quite sensitive to lateral changes in conductivity, and thus suitable field experiments using Geomagnetic Depth Sounding (GDS), MT, AMT and Deep Electrical Sounding (DES) techniques are being designed. It may be helpful, in this connection, to arrive at a quantitative insight by a priori numerical experiments as have been carried out for the Ganga Basin (VozOFF, 1984), using them in designing and optimizing suitable field campaigns. ILKISIK and JONES (1984) have also emphasized the need for 
pre-survey evaluation of MT-AMT methods utilising the Singular Value Decomposition (SVD) technique for a basalt-covered area of SE Anatolia (Turkey).

In view of the difficulty of LVL outlined above, it should be mentioned here that the model of the crustal section used here has been derived (KAILA, 1986) using an indirect method, based on statistical criteria for resolving a hidden LVL in seismic refraction prospecting (KAILA et al., 1981).

\section{The Area under Study and the Model}

As may be seen from Fig. 2, the geological area falls within the central part of the Deccan Trap region. The Ujjain-Mahan DSS profile crosses the Narmada-Son lineament (at SP 95) and Tapti River at Nepanagar (SP 200). At Sanawad on the central part, it comes into contact with the pre-Cambrian sediments (SP 95). From the DSS data both shallow (up to $\sim 3 \mathrm{~km}$ ) as well as deeper (up to $\sim 40 \mathrm{~km}$ ) crustal sections have been recovered; we confine our attention to the former and relatively short period variations because our interest in this study lies in using the MT/AMT methodology for the delineation of possible sedimentary structures underlying the trap rock.

The model considered in this numerical study is representative of structures below the profiles $\mathrm{AA}^{\prime}$ and $\mathrm{BB}^{\prime}$ as shown in Fig. 2. The profile $\mathrm{AA}^{\prime}$ from the Narmada River-Mahan is in the NW-SE direction and its top layer consists of basalts. Below this lies a sedimentary layer consisting of Precambrian and Mesozoic age groups separated by a fault near Dorwa (SP 135). From the deep reflection study (Fig. 5 of KAILA, 1986) this fault appears to extend even up to Moho. The thickness of the sedimentary layer varies from 600 to $1700 \mathrm{~m}$, and it is characterized by a seismic velocity $V_{\mathrm{p}}=3.2 \mathrm{~km} / \mathrm{s}$. This sedimentary structure in turn rests over the Precambrian basement with velocity $V_{\mathrm{p}}=5.8 \mathrm{~km} / \mathrm{s}$. A deeply buried fault at SP 160 seems to control the maximum thickness of the sedimentary basin. It appears that the fault near the Tapti River (SP 200) forms a pair with that at Dorwa for the development of sedimentary structure. The presence of deep faults over the profile $\mathrm{AA}^{\prime}$ is corroborated by high regional heat flow values (RAVI SHANKER, 1988) as shown in Fig. 2. The significant lateral variation obtained in the heat flow over the area not only indicates tectonic mobilization but may also affect the subsurface electrical conductivity. Between the Tapti (SP 200) and Wan (SP 240) rivers three topographic features $\left(T_{1}, T_{2}\right.$ and $\left.T_{3}\right)$ exist. It is of interest to note that heat flow values across the profile $\mathrm{AA}^{\prime}$ reach their maximum over this region. To construct the models, various parametric values as given in Table 1 have been taken from SUBRAHMANYAM (1987) and CLARK (1966). The special features of the section under profile $A A^{\prime}$ are i) faults $\left(F_{1}, F_{2}\right)$ and ii) topographic features $\left(T_{1}, T_{2}, T_{3}\right)$. The other NNE-SSW oriented profile $\mathrm{BB}^{\prime}$ has a thin surface coating of alluvium with velocity $V_{\mathrm{p}}=2.5 \mathrm{~km} / \mathrm{s}$, overlying the traps. Below the traps lie Mesozoic sediments with an inclined basement thinning towards the south. 

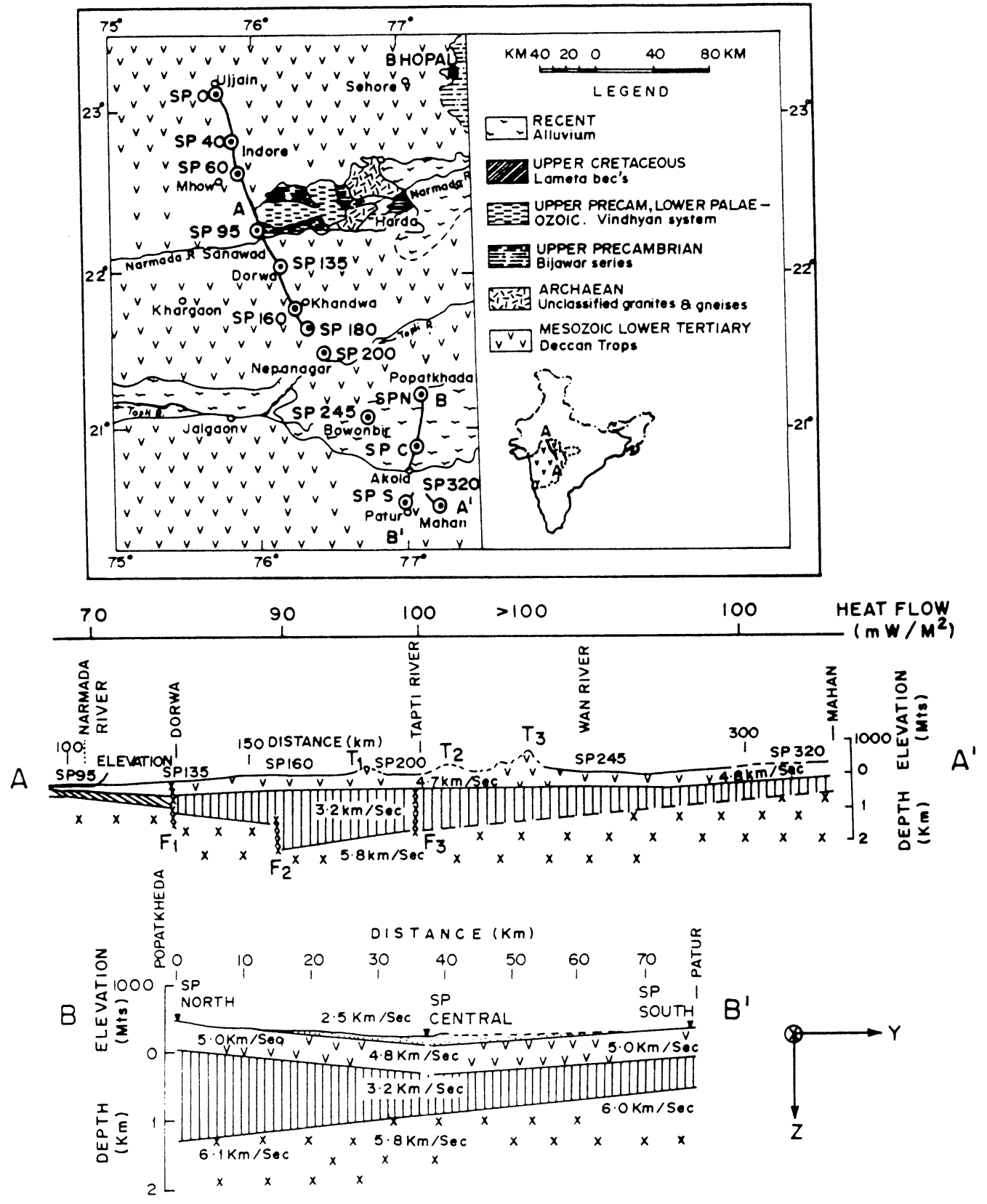

Fig. 2. (Top) Geology of the area over which profiles $\mathrm{AA}^{\prime}$ and $\mathrm{BB}^{\prime}$ are taken (inset gives the location of profiles). (Bottom) The seismic depth sections along $\mathrm{AA}^{\prime}$ and $\mathrm{BB}^{\prime}$. 
Table 1. Conductivities of different geological formations (after Subrahmanyam, 1987 and Clark, 1966).

\begin{tabular}{lcc}
\hline \multicolumn{2}{l}{ Geological formation } & Conductivity $(\mathrm{S} / \mathrm{m})$ \\
\hline Basalts & Dry & $10^{-4}-10^{-7}$ \\
& Wet & $10^{-2}-10^{-4}$ \\
Sediments & Dry & $10^{-3}-10^{-5}$ \\
& Wet & $10^{-1}-10^{-2}$ \\
Granites & Dry & $10^{-6}-10^{-8}$ \\
& Wet & $10^{-4}-10^{-6}$ \\
\hline
\end{tabular}

\section{Numerical Results and Discussion}

The finite element formulation employed here, due to WANNAMAKER et al. $(1985,1987)$, utilizes a linear interpolation of the unknown field parallel to the strike over triangular subdomains, along with the Galerkin approach of basis weighting, to arrive at a system of linear equations which approximates the Helmholtz equation. An important requirement for obtaining results of desired accuracy is the design of a proper mesh, following certain rules of thumb (WANNAMAKER et al., 1985). Dirichlet boundary conditions are applied at all external mesh boundaries. Zero boundary conditions are imposed at the left edge, because the mesh is so designed that its edges may be considered sufficiently remote from the conductive inhomogeneity. The left extreme is therefore used to normalize the electric and magnetic field components induced due to anomalous zones.

The four electromagnetic characteristics studied here are the magnitudes of the normalized electric and magnetic field components $\left(\left|E_{i}^{n}\right|\right.$ and $\left.\left|H_{i}^{n}\right|\right)$, the apparent resistivity $\rho_{\mathrm{a}}=0.2 T|Z|^{2}$ and phase $\phi=\arctan (\operatorname{Im} Z / \operatorname{Re} Z)$. Where superscript $n$ denotes normalization and subscript $i$ represents $x, y$, or $z, Z$ is the impedance (the ratio of transverse electric to magnetic field components) and $T$ is the period of the inducing field. In the following, $E$ and $H$ field components should be considered as representing the normalized magnitudes as the superscript $n$ and magnitude symbol are dropped.

The behaviour of the four elements have been examined for possible values (Table 2 ) of the i) thickness $\left(t_{1}\right)$ and conductivity $\left(\sigma_{1}\right)$ of the basaltic layer at the top (zone 1; Fig. 3), ii) conductivity $\left(\sigma_{3}\right)$ of a sandwiched layer of the Mesozoic sediments (zone 3; Fig. 3), iii) conductivity $\left(\sigma_{4}\right)$ of the Precambrian basement (zone 4; Fig. 3) and iv) period ( $T$ ) of the inducing field, which controls the extent of screening by the outer layers (or the intensity of induction in deeper parts of the model). Variations of these e.m. characteristics have been studied for both the Eand B-polarization modes. Numerical estimates are also obtained for single-site sounding experiments and the influence of surface as well as buried topographies. 
Table 2. Various parametric values used in numerical modelling.

\begin{tabular}{|c|c|c|c|c|c|}
\hline & Parameters & $\begin{array}{l}\text { Period } \\
(\mathrm{sec})\end{array}$ & $\begin{array}{l}\text { Thickness } \\
(\mathrm{m})\end{array}$ & $\begin{array}{c}\text { Zones as } \\
\text { shown in } \\
\text { Fig. 4A }\end{array}$ & $\begin{array}{l}\text { Conductivity } \\
\qquad(\mathrm{S} / \mathrm{m})\end{array}$ \\
\hline$[\mathrm{A}]$ & Profile $\mathrm{AA}^{\prime}$ & & & & \\
\hline (i) & $\begin{array}{l}\text { Thickness } \\
\text { of basaltic } \\
\text { layer }\left(t_{1}\right)\end{array}$ & 0.1 & $\begin{array}{l}0,100 \\
400,1000\end{array}$ & $\begin{array}{l}1 \\
2 \\
3 \\
4\end{array}$ & $\begin{array}{l}0.005 \\
0.01 \\
0.02 \\
10^{-4}\end{array}$ \\
\hline (ii) & $\begin{array}{l}\text { Conductivity } \\
\text { of basaltic } \\
\text { layer }\end{array}$ & 0.1 & $\begin{array}{l}\text { As per } \\
\text { model }\end{array}$ & $\begin{array}{l}1 \\
2,3,4\end{array}$ & $\begin{array}{l}0.01,0.005,10^{-3} \\
\text { As in case (i) }\end{array}$ \\
\hline (iii) & $\begin{array}{l}\text { Conductivity } \\
\text { of Mesozoic } \\
\text { sediments }\end{array}$ & 0.1 & $\begin{array}{l}\text { As per } \\
\text { model }\end{array}$ & $\begin{array}{l}3 \\
1,2,4\end{array}$ & $\begin{array}{l}0.1,0.02,0.01 \\
\text { As in case (i) }\end{array}$ \\
\hline (iv) & $\begin{array}{l}\text { Conductivity } \\
\text { of granitic } \\
\text { basement }\end{array}$ & 0.1 & $\begin{array}{l}\text { As per } \\
\text { model }\end{array}$ & $1,2,3$ & $\begin{array}{l}0.005,10^{-4}, 10^{-7} \\
\text { As in case (i) }\end{array}$ \\
\hline (v) & $\begin{array}{l}\text { Period of } \\
\text { exitation }\end{array}$ & $\begin{array}{l}0.01, \\
0.1,1, \\
10,100\end{array}$ & $\begin{array}{l}\text { As per } \\
\text { model }\end{array}$ & \multicolumn{2}{|c|}{ As in case (i) } \\
\hline [B] & Profile $\mathrm{BB}^{\prime}$ & $\begin{array}{l}0.1,1 \\
10,100\end{array}$ & $\begin{array}{l}\text { As per } \\
\text { model }\end{array}$ & $\begin{array}{l}5 \\
1,3,4\end{array}$ & $\begin{array}{l}0.1 \\
\text { As in case (i) }\end{array}$ \\
\hline
\end{tabular}

\section{Thickness $\left(t_{1}\right)$ of the Basaltic Cover (Fig. 3A)}

The thickness of the basaltic cover over the Deccan Trap region varies from 100 to $2000 \mathrm{~m}$, with the maximum thickness near the western margin. Along the profile $\mathrm{AA}^{\prime}$ (Fig. 2) the basaltic cover thickness $\left(t_{1}\right)$ varies between 100 and $200 \mathrm{~m}$ near the Narmada River (left extreme of the profile) and $t_{1}$ reaches the value of about $1000 \mathrm{~m}$ at a place $20 \mathrm{~km}$ north of Bawanbir. For the E-Polarization mode one observes in Fig. 3A-I that the screening of the fault $\left(\mathrm{F}_{1}\right)$, in the $E_{x}$ response is enhanced by an increase in the thickness $\left(t_{1}\right)$ of the basaltic layer. The underlying sedimentary layer (or structure) may be observed up to $t_{1}<300 \mathrm{~m}$. The imprints of surface topography are, however, not affected by variations in the trap thickness $\left(t_{1}\right)$ for this period. In the $H_{y}$ variation, with increasing $t_{1}$ the deeper feature (say $\mathrm{F}_{2}$ ) (Fig. 3A-II) is gradually masked. The response behaviours over the near-surface fault $\left(F_{1}\right)$ differ from that over the deeper one $\left(F_{2}\right)$, as with an increase in trap thickness $F_{1}$ is screened to a greater extent than $F_{2}$. The reflection of the surface features $\left(T_{1}, T_{2}\right.$ and $\mathrm{T}_{3}$ ) show an interesting pattern in the $H_{y}$ variation: at a trap thickness of $100 \mathrm{~m}$, none of the surface features can be seen; at intermediate thickness values $\left(100<t_{1}<\right.$ $1000 \mathrm{~m})$, say $t_{1}=300 \mathrm{~m}$, we observe a clear imprinting of all three features $\left(\mathrm{T}_{1}, \mathrm{~T}_{2}\right.$ and 
A

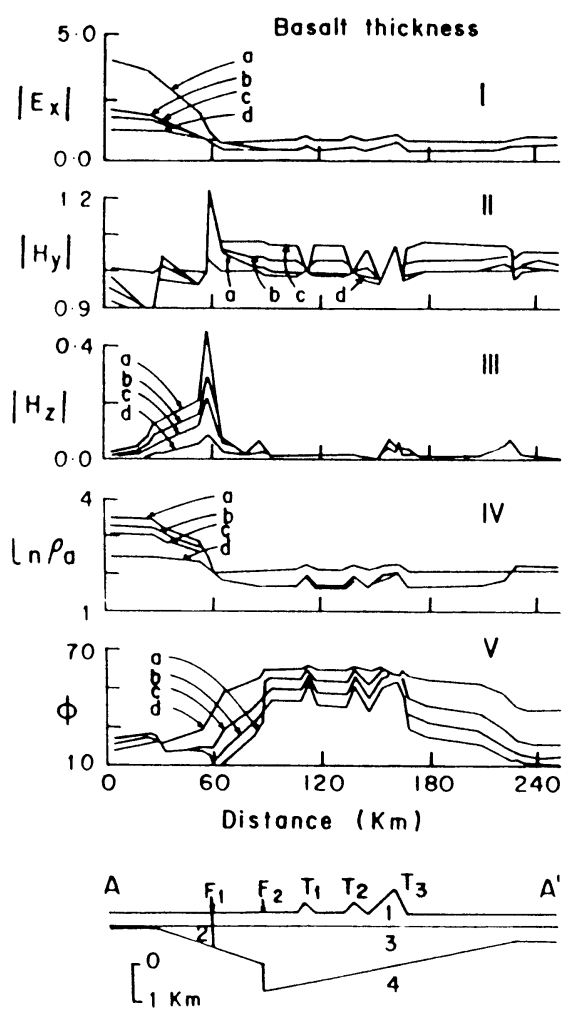

B
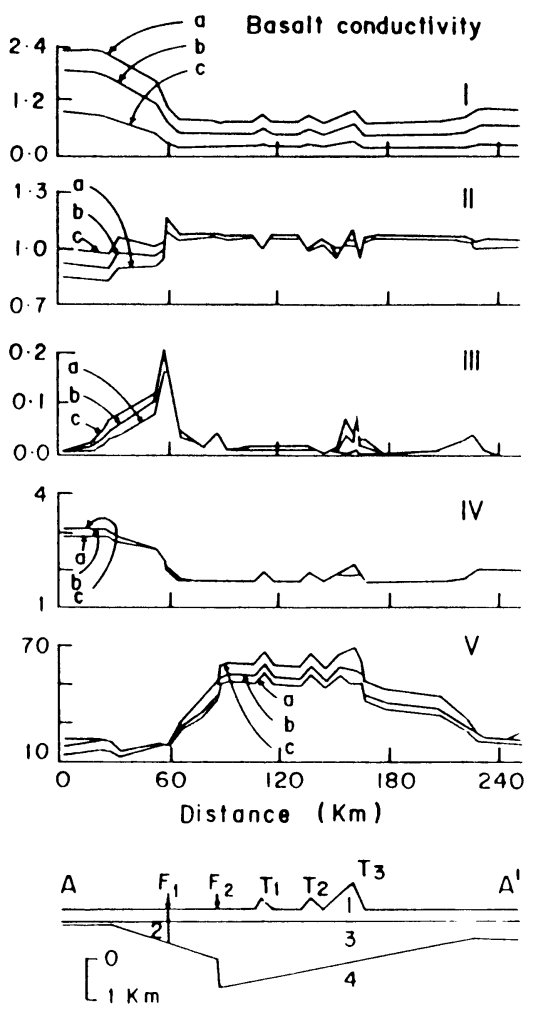

Fig. 3. EM response characteristics (E-pol) over the profile $\mathrm{AA}^{\prime}$. [A] Variation with thicknesses 0 (a), 100 (b), 300 (c) and 1000 (d) in mts of basaltic layer $\left(t_{1}\right)$. [B] Variation with different conductivities 0.01 (a), 0.005 (b) and 0.001 (c) in $\mathrm{S} / \mathrm{m}$ of basaltic layer (Zone 1).

$\mathrm{T}_{3}$ ) and at $t_{1}=1000 \mathrm{~m}$ only the biggest one, $\mathrm{T}_{3}$, manifests. This indicates an optimization of the response sensitivity in terms of a parametric combination consisting of the period $(T)$, thickness of the trap $\left(t_{1}\right)$ and conductivity of the basaltic cover $\left(\sigma_{1}\right)$. For the $H_{z}$ variation the sharp lateral changes alone are seen (Fig. 3A-III).

At large trap thickness of $1000 \mathrm{~m}$, the contribution to $\rho_{\mathrm{a}}$ from the underlying sedimentary structure is nearly screened, as seen in Fig. 3A-IV. Further, the imprint of the fault $\left(\mathrm{F}_{1}\right)$ also decreases with the increase in the trap thickness. For the phase $(\phi)$ characteristics (Fig. 3A-V) the signatures of $F_{1}$ and $F_{2}$ decrease differentially with the increase in the thickness of basalt. Interestingly, the reflections of $T_{1}, T_{2}$ and $\mathrm{T}_{3}$ are screened at trap thickness equal to $1000 \mathrm{~m}$, relative to that at the trap thickness equal to $300 \mathrm{~m}$. For the B-polarization mode, $\mathrm{T}_{1}$ and $\mathrm{T}_{2}$ are not reflected in the $\rho_{\mathrm{a}}$ characteristics (Fig. 7-I). Further, on decreasing the trap thickness, as 
expected, the screening of the deeper part is reduced so that the sedimentary structure embedded below the basaltic cover gets reflected better. In the phase $(\phi)$ variation (Fig. 7-II), with an increase in trap thickness the shallow fault $\left(F_{1}\right)$ is seen better, while the response due to the deeper fault $\left(\mathrm{F}_{2}\right)$ is reduced. The phase characteristics of the $T_{1}, T_{2}$ and $T_{3}$ are also masked with an increase in the trap thickness.

\section{Conductivity $\left(\sigma_{1}\right)$ of the Basaltic Cover (Fig. 3B)}

As can be seen from Table 1, the conductivity values of basalts vary depending upon the moisture content. Porosity and interconnectivity of the rock matrix are also factors in this regard. The existence of faults/fractures may also significantly change the conductivity because water, minerals and temperature attend them.

In the E-polarization mode a smoothing of the surface topographic features is seen (Fig. 3B-I) in the $E_{x}$ characteristics with the decrease in the surface layer conductivity $\left(\sigma_{1}\right)$. The manifestation of the near surface fault $\left(\mathrm{F}_{1}\right)$ increases as $\sigma_{1}$ is increased. For the $H_{y}$ response, the decrease in $\left(\sigma_{1}\right)$ causes a reduction in the effect of the fault $F_{1}$, but enhances that due to the deeper discontinuity $\left(F_{2}\right)$ (Fig. 3B-II). In the $H_{z}$ variation (Fig. 3B-III), with a decrease in $\sigma_{1}$ the fault $\left(\mathrm{F}_{2}\right)$ is seen better, while the signatures of the surface features $\left(T_{1}, T_{2}\right.$ and $\left.T_{3}\right)$ are reduced. But as can be seen from Fig. 3B-IV, in the case of $\rho_{\mathrm{a}}$ variation, the surface features are better reflected at lower values of the trap conductivity $\left(\sigma_{1}\right)$. For the B-polarization mode, as in E-polarization, only the lateral changes are sharply reflected (Fig. 7-III).

\section{Conductivity $\left(\sigma_{3}\right)$ of the Mesozoic Sediments (Fig. 4)}

The variation in conductivity of the sediments $\left(\sigma_{3}\right)$ may depend upon their age (VOZOFF, 1972) and tectonic history characterized by tectophysical parameters like porosity, interconnectivity, presence of water, temperature etc. Their contrast with the basement and overlying trap rocks is of critical importance in delineation of the target sedimentary structure below the basaltic cover. The range of the $\sigma_{3}$ values are given in Table 2 .

For the E-polarization mode it is seen (Fig. 4-I) that with an increase in the conductivity of the sediments, the features $\mathrm{T}_{1}, \mathrm{~T}_{2}$ and $\mathrm{T}_{3}$ for the $E_{x}$ variation are better manifested. One also notices an increase in the signatures of the fault $F_{1}$ with an increase in the conductivity contrast between the Vindhyan (zone 2; Fig. 4) and Mesozoic (zone 3; Fig. 4) sediments. But the imprint of the deeper fault $\left(\mathrm{F}_{2}\right)$ gets masked by the increase in sediment conductivity. In the $H_{y}$ variation (Fig. 4-II), we see a similar behaviour with respect to faults $\left(F_{1}\right.$ and $\left.F_{2}\right)$ and surface features $\left(T_{1}, T_{2}\right.$ and $\mathrm{T}_{3}$ ). The behaviour of $H_{z}$ which reflects only the major lateral contrast (Fig. 4-III) is also similar to that of the $H_{y}$ variation. The $\rho_{\text {a }}$ characteristics (Fig. 4-IV) follow the pattern of the $E_{x}$ variation. In the B-polarization mode and for the parameters considered here, the $\rho_{\text {a }}$ variation seems less sensitive to changes in surface topography than the lateral variation (Fig. 7-V) at depth. The phase 

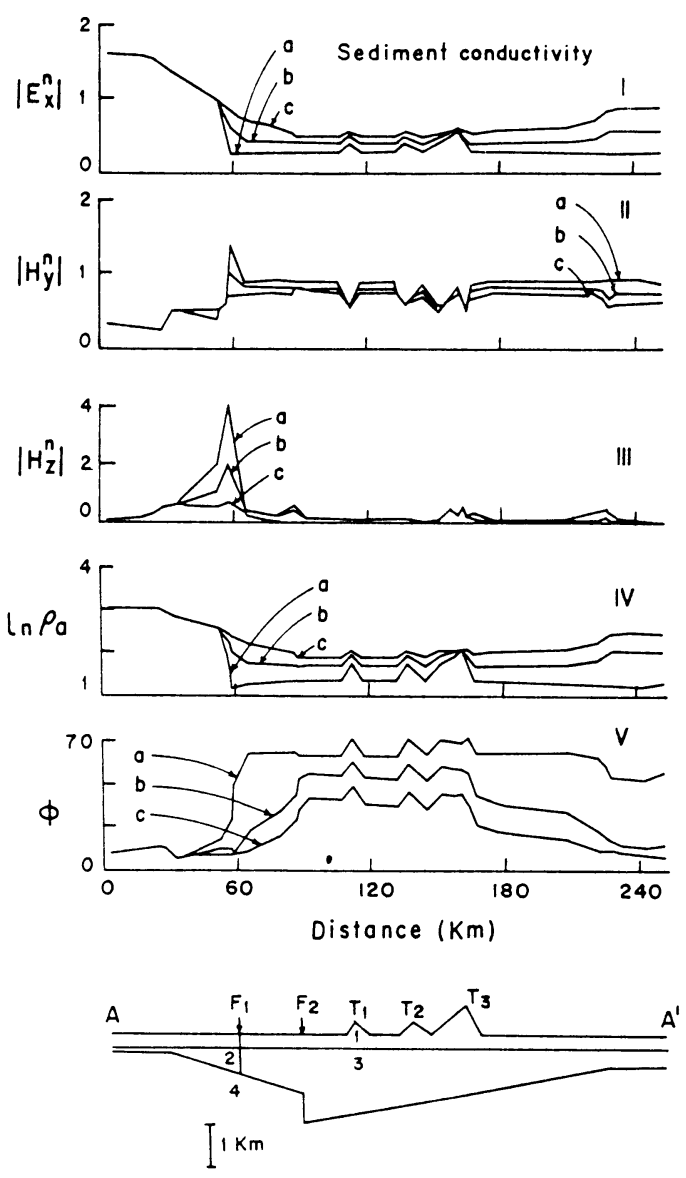

Fig. 4. EM response characteristics (E-pol) over $\mathrm{AA}^{\prime}$ for variation with conductivity 0.1 (a), 0.02 (b) and 0.01 (c) in $\mathrm{S} / \mathrm{m}$ of Mesozoic sediments (Zone 3).

component $(\phi)$, however, shows (Fig. 4-V) much less screening with increases in $\sigma_{3}$, and thus the deeper fault at $\mathrm{F}_{2}$ is seen even for lower $\sigma_{3}$ values. In the B-polarization mode, the effect due to fault $\left(\mathrm{F}_{2}\right)$ is enhanced for lower $\sigma_{3}$ values.

\section{Basement Conductivity $\left(\sigma_{4}\right)$ (Fig. 5)}

In the E-polarization mode for the $E_{x}$ variation, the increases in contrasts between the sediments $(2,3)$ and the basement $(4)$ is most clearly reflected near the fault $\mathrm{F}_{1}$ (Fig. 5-I). On the righthand side of fault $\mathrm{F}_{1}$, the $E_{x}$ response is less for lower values of the basement conductivity $\left(\sigma_{4}\right)$. Thus an interesting reversal in the $E_{x}$ response behaviour is seen on two sides of fault $F_{1}$. While the signatures of the surface topography are enhanced for higher basement conductivity, the deeper fault 

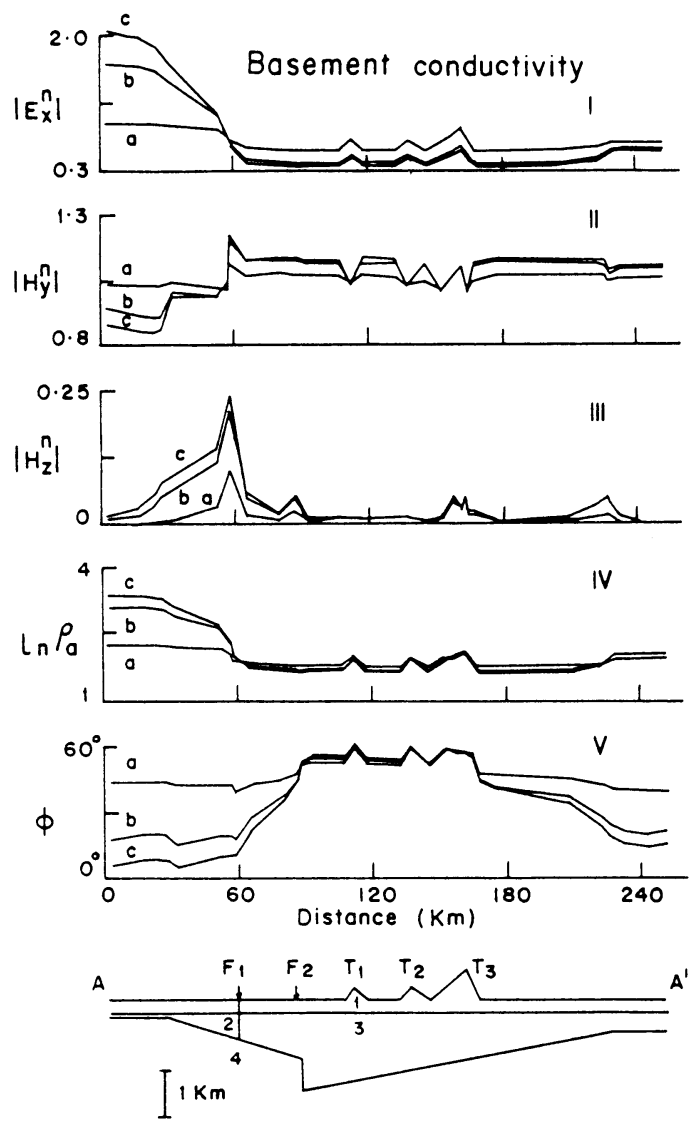

Fig. 5. EM response characteristics (E-pol) over $\mathrm{AA}^{\prime}$ for variation with conductivity $5 \times 10^{-3}(\mathrm{a}), 10^{-4}(\mathrm{~b})$ and $10^{-7}$ (c) in $\mathrm{S} / \mathrm{m}$ of basement (Zone 4$)$.

$\mathrm{F}_{2}$ seems largely screened due to highly conducting thick sediments above it and is seen only slightly for smaller basement conductivity values $\left(\sigma_{4}\right)$.

The sensitivity of the $H_{y}$ response to the lateral changes can again be noticed. A rise in the basement conductivity in turn decreases the degree of lateral changes at $\mathrm{F}_{1}$, which are quite markedly picked up in the $H_{y}$ response (Fig. 5-II). The amplitudes of the imprints of $\mathrm{T}_{1}, \mathrm{~T}_{2}$ and $\mathrm{T}_{3}$ decrease with increases in $\sigma_{4}$. For the $H_{2}$ response, all the lateral variations are faithfully reflected except for the smaller surface features $\left(T_{1}\right.$ and $\left.T_{2}\right)$. Further, the increase in contrast between the sediments and the basement seems to substantially enhance the $H_{2}$ variations at $F_{1}$ and $F_{2}$. One also notices quite a conspicuous manifestation of the deeper fault $\left(\mathrm{F}_{2}\right)$ in contrast to its faint expression in the $E_{x}$ and $H_{y}$ variations. Another observation of some significance is that the effect of lateral changes in electrical conductivity appears to 
propagate over much larger distances if resistivity of the basement is greater. This may be due to the fact that for highly resistive substrata, the influence of induced currents due to the lateral changes take longer distances to adjust in less conductive media owing to much slower rates of decay (JONES, 1983) in the lateral direction.

\section{Period of Exitation (Fig. 6)}

\section{E-polarization mode}

One observes from the variation of normalized $E_{x}$ that it is maximized around $0.1 \mathrm{sec}$ (Fig. 6A-I). For $T>0.2 \mathrm{sec}$ the effect of surface features disappears, implying that the (nearly $300 \mathrm{~m}$ thick) surface layer has become nearly transparent to the inducing field. The fault $\left(\mathrm{F}_{1}\right)$ is seen clearly at $T>1 \mathrm{sec}$ and gets screened at lower periods $(T<0.1 \mathrm{sec})$, but the deeper fault $\left(\mathrm{F}_{2}\right)$ can be seen even at lower periods. The shape of the basin seems to be revealed between the period range $0.1-1 \mathrm{sec}$, but at lower periods $(T<0.1 \mathrm{sec})$, owing to the enhanced screening, this manifestation disappears. The variation of $H_{y}$ is more sensitive to lateral inhomogeneities, as seen in Fig. 6A-II. Secondly, in contrast to $E_{x}$, the basin is reflected here in an inverted sense and seen even at higher periods. The maximum response for both cases is observed between the period range 1 and $10 \mathrm{sec}$. As before, the profile for $H_{z}$ reflects

[A]
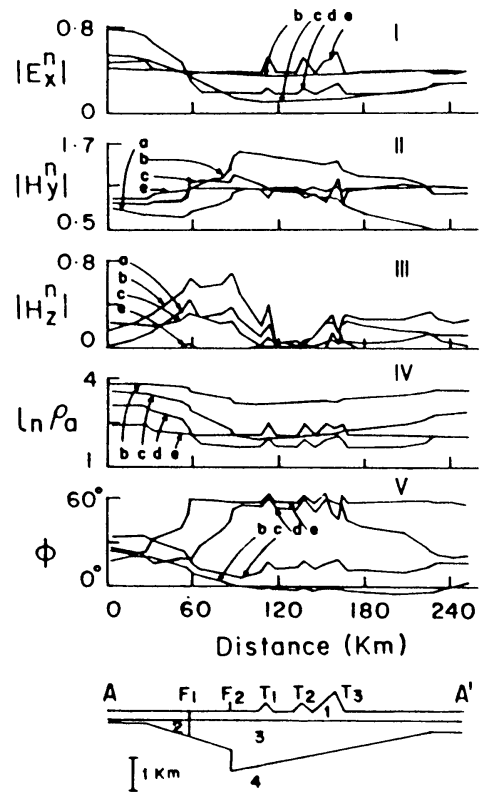

[B]

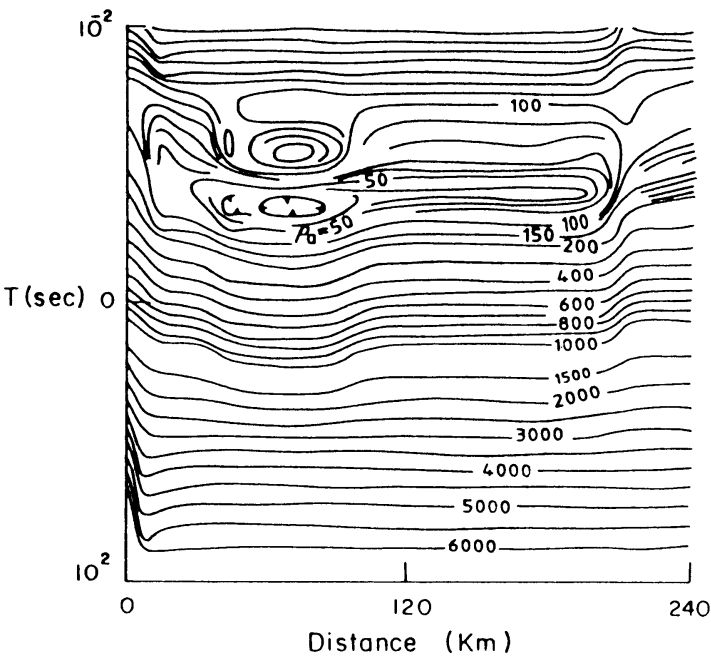

Fig. 6. [A] Variation (E-pol) over $\mathrm{AA}^{\prime}$ with the period (T) of exitation 100 (a), 10 (b), 1 (c), 0.1 (d) and 0.01 (e) in Sec. [B] Variation of the $\rho_{\mathrm{a}}$ at different periods and direction along the profile AA'. 

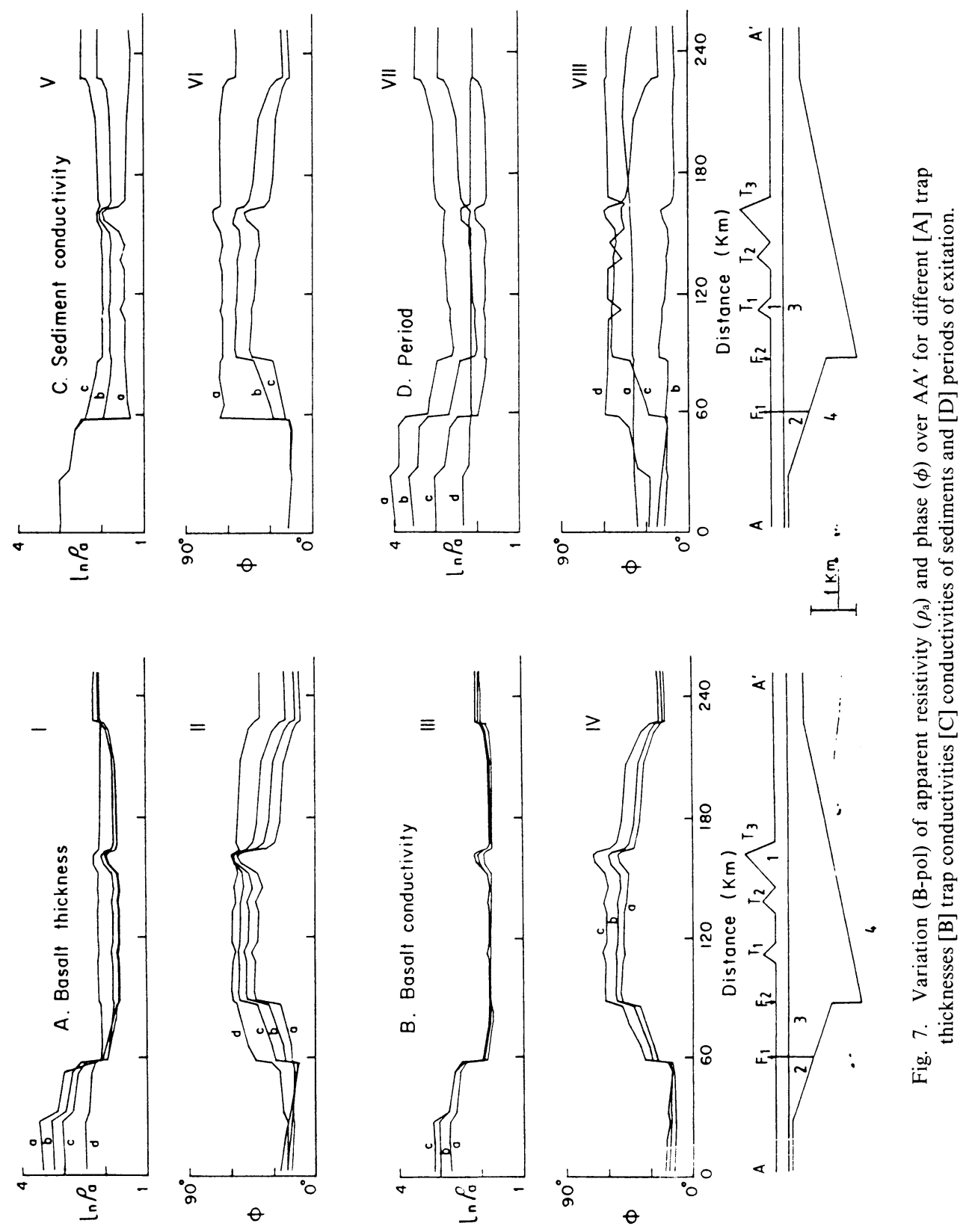
only the lateral discontinuities (Fig. 6A-III). For $T<1 \mathrm{sec}$ a progressive screening of deeper features is noticed on the lefthand side of the section and emergence of surface topographic features on the righthand side of the section. For the range $T=1$ to $10 \mathrm{sec}$, deeper features $\left(F_{1}, F_{2}\right)$ are reflected better; with a decrease in the exitation period there is a marked improvement in the signatures of $T_{1}, T_{2}$ and $T_{3}$ also. The apparent resistivity $\left(\rho_{\mathrm{a}}\right)$ profile (Fig. 6A-IV) is similar to that of the $E_{x}$ response (Fig. $6 \mathrm{~A}-\mathrm{I})$. In the case of the phase $(\phi)$ response with a decrease in period, the effect of the basement reduces (Fig. 6A-V) while that of topography increases; a response inversion is also seen between 1 and $0.1 \mathrm{sec}$. For a more detailed and diagnostic analysis a pseudo-section is given in Fig. 6B, which plots the apparent resistivity for a number of periods ranging from $10^{-2}$ to $10^{2} \mathrm{sec}$ along the profile $\mathrm{AA}^{\prime}$. From this figure clustering of apparent resistivity contours may be easily noticed for the periods of 0.03 to $0.3 \mathrm{sec}$, one finds that the underlying sedimentary structure seems to show up best at $T \sim 0.1 \mathrm{sec}$.

\section{B-polarization mode}

The apparent resistivity $\left(\rho_{\mathrm{a}}\right)$ is far more sensitive to lateral changes in the conductivity for $T<0.1 \mathrm{sec}$. At $T=0.01 \mathrm{sec}$, only the largest surface feature $\left(\mathrm{T}_{3}\right)$ is reflected (Fig. 7-VII). As the period increases, the deeper discontinuities and the shape of the sedimentary structure is faithfully reflected in this mode, in comparison to the E-polarization mode. For the phase $(\phi)$ component, the basin shape is reflected in the period range of $0.1-1 \mathrm{sec}$ (Fig. 7-VIII). At higher periods ( $T=10 \mathrm{sec}$ ), the topographic heterogeneities $\left(T_{1}, T_{2}\right.$ and $\left.T_{3}\right)$ are smoothed out, whereas at lower periods $(T=0.01 \mathrm{sec})$ the deeper fault $\mathrm{F}_{2}$ is screened.

\section{Single Site Sounding (Fig. 8)}

Figure 8 shows the variation of the apparent resistivity $\left(\rho_{\mathrm{a}}\right)$ with the period of excitation $(T)$ at three different locations $\left(\mathrm{L}_{1}, \mathrm{~L}_{2}\right.$ and $\left.\mathrm{L}_{3}\right)$ over the profile $\mathrm{AA}^{\prime}$. One notices here that in general the apparent resistivity increases with the period, however, owing to the embedded conductive heterogeneities, the increase in $\rho_{\mathrm{a}}$ is not smooth. For the two locations $\left(\mathrm{L}_{2}\right.$ and $\left.\mathrm{L}_{3}\right)$ one notices lows in $\rho_{\text {a }}$ due to the conductive sediments underlying the trap rocks, in the period range 0.1 to $1 \mathrm{sec}$. For the B-polarization case, the maximum and minimum in the apparent resistivity are seen more clearly.

The behaviour of electromagnetic sounding characteristics may be understood in terms of an interplay between effects due to variations in $\sigma$ and $T$. Thus at higher periods $(T)$, the increase in the skin depth enhances the influence of the inducing field to greater depths. The intensity of the induced currents, however, will be 1) more for higher values of the conductivity at a given depth and period and 2) less for specified conductivity and depth, if the period is increased, following the law of induction. It is superposition of these two influences which is responsible for the morphology of various induction characteristics for the parametric space of the chosen model. 

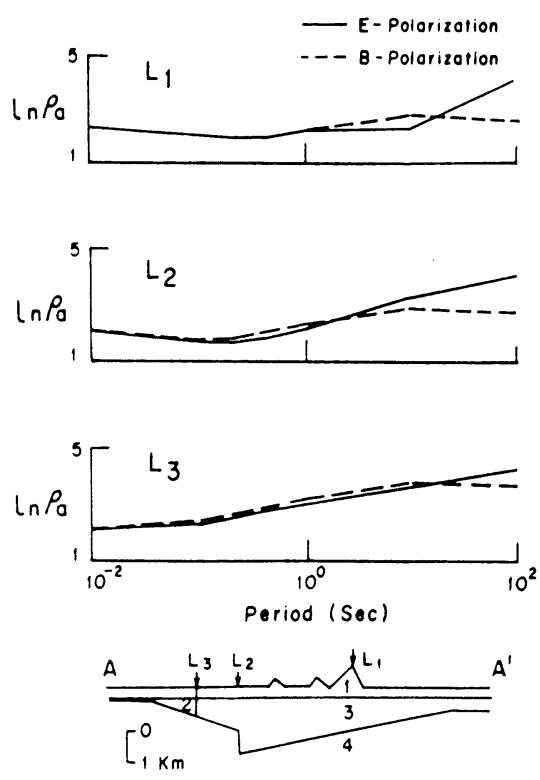

Fig. 8. Variation of apparent resistivity $\left(\rho_{\mathrm{a}}\right)$ (for both E- and B-pol modes) over profile $\mathrm{AA}^{\prime}$ at three locations $\left(\mathrm{L}_{1}, \mathrm{~L}_{2}, \mathrm{~L}_{3}\right)$.

\section{Results for the Profile BB' (Fig. 9)}

Here the top layer (Fig. 2) in the central region of the profile (BB') is a thin and nonuniform coating of alluvium (zone 5, Fig. 9) with a max. thickness of $100 \mathrm{~m}$ having conductivity $\sigma_{5}=0.1 \mathrm{~S} / \mathrm{m}$. Thus in the central part of the profile $\mathrm{BB}^{\prime}$, the basaltic layer (zone 1) is sandwiched between conductive sediments (zone 3) and alluvium. The base of the sedimentary layer reveals a smooth variation of thickness. From Fig. 9-I we see that between periods from 1 to $10 \mathrm{sec}$, the shape of the basement is reflected in the $E_{x}$ response. Further, the lateral contrasts at the junctions $S_{1}$ and $S_{2}$ between the alluvium and trap (zones 1 and 5) show up in the form of shoulders. The $E_{x}$ response increases with the period near both ends of the profile $\mathrm{BB}^{\prime}$, while for the $H_{y}$ response, for a change of period from 1 to $10 \mathrm{sec}$, an inversion of characteristics is noticed (Fig. 9-II). For lower periods $(T<0.1)$, as expected the surface conductivity contrasts predominate the induction behaviour. In the $H_{z}$ variation, the anomaly due to the near surface lateral changes gets substantially magnified with a decrease in the period (Fig. 9-III), while for longer periods $(T=10 \mathrm{sec})$ it is reduced markedly. The deeper lateral changes, which are masked at short periods ( $T \sim 0.01 \mathrm{sec}$ ), begin to get reflected for $T>1 \mathrm{sec}$, as can be seen in the central portion of the profile for $\rho_{\mathrm{a}}$ (Fig. 9-IV). The apparent resistivity first shows a decrease and then increases for longer periods, with the rate of increase being larger on the righthand side of the profile. In the central part of the profile, the 

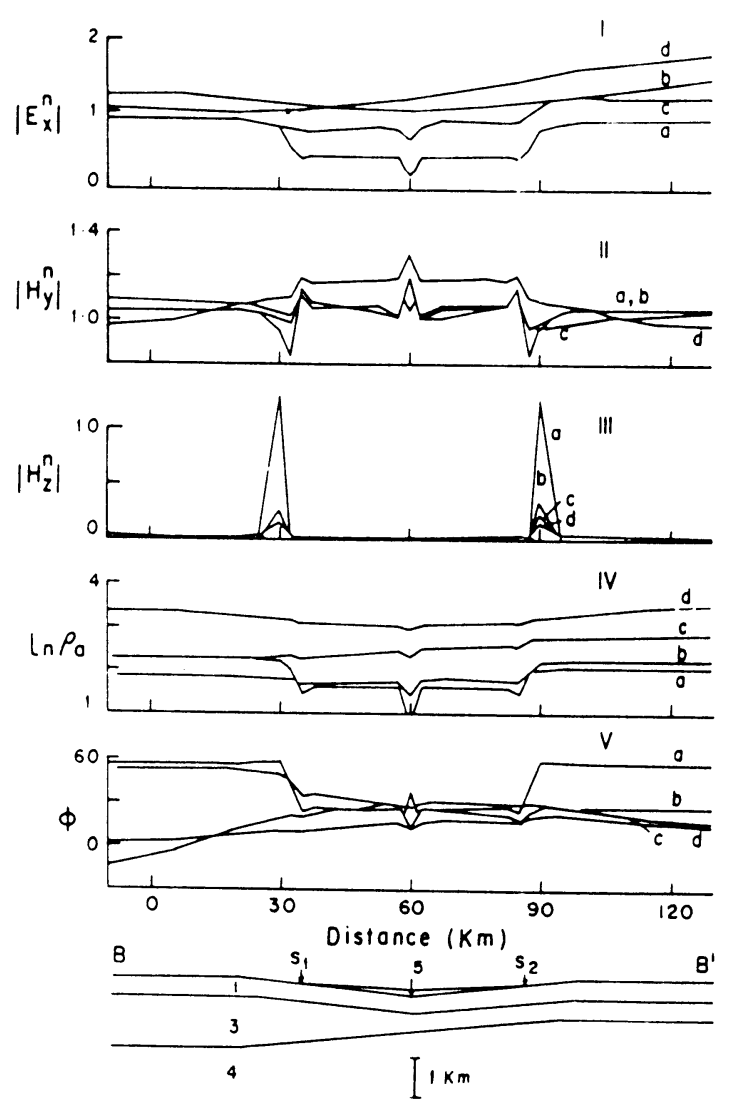

Fig. 9. Variation of the response characteristics (E-pol) over $\mathrm{BB}^{\prime}$ for different periods $(T)$ of exitation 0.1 (a), 1 (b), 10 (c) and 100 (d) in sec.

lateral contrast at the interface between trap rocks and alluvium can be seen up to $T \sim 0.1 \mathrm{sec}$, but is not significant at higher periods. The central low in $\rho_{\mathrm{a}}$ at $T=0.01$ and $0.1 \mathrm{sec}$ may have been caused by the high conductivity of the alluvium.

12. Influence of Topography (Fig. 10)

Topographic features may exist on the surface layer as well as buried in deeper regions. We have described above how the imprints of surface topography $\left(T_{1}, T_{2}\right.$ and $T_{3}$ ) vary with conductivity and thickness parameters. The possible reflection/ delineation of buried topography is also of equal importance because most of the investigations in the Deccan trap region aim at deciphering the possible existence of sediments of Mesozoic age (or older) underlying the trap. From Fig. 3A of the DSS section, there is a buried fault $\left(F_{2}\right)$ of throw $1.6 \mathrm{~km}$ interfacing the conductive 


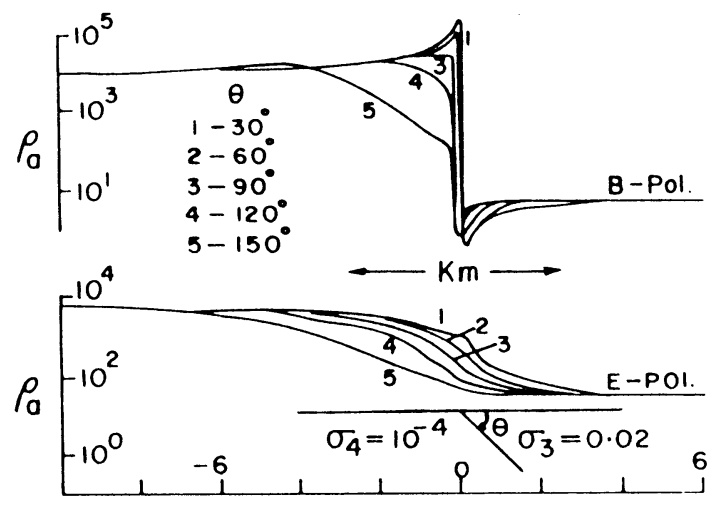

Fig. 10. Variation of apparent resistivity $\left(\rho_{\mathrm{a}}\right)$ with $\operatorname{dip}(\theta)$ of the fault across the Mesozoic sediments and the basement.

sediments and resistive basement. The lower boundary of the sedimentary layer (zone 3; Fig. 3) gradually rises on the right of this fault $\left(F_{2}\right)$ up to a depth of $800 \mathrm{~m}$. This embedded topography becomes prominent due to conductivity contrast. Figure 10 shows the effect of the fault and its dip on the apparent resistivity at $T=0.1 \mathrm{sec}$ for both E- and B-polarization modes. Besides variation with the dip, one also notices that a significant difference exists in the apparent resistivity variation obtained for the two polarization modes. The B-polarization is apparently more sensitive to the subsurface faults/boundaries.

\section{Concluding Remarks}

Due to geological, tectonic and economic significance, geophysical probing of the large spread over the Deccan flood basalt of the Indian subcontinent is being mounted using seismic as well as electrical methods. The numerical experiment carried out here will hopefully assist us in arriving at quantitative estimates of the influence of possible parametric values. Some of the main results are:

1) The identification of the period interval where the reflection of surface and embedded faults and the shape of the basin are optimally delineated.

2) Screening of $H_{y}$ and $H_{z}$ components seems relatively less than that of $E_{x} . H_{z}$ reflects lateral variations.

3) Apparent resistivity in the B-polarization mode is far more sensitive to lateral changes and reflects the inner structure up to higher periods in comparison to the E-polarization mode.

4) The amplitude of phase (B-polarization) increases with an increase of $t_{1}$ in the shallow fault $\left(F_{1}\right)$ and is reversed in the deeper fault $\left(F_{2}\right)$.

5) The increase in the $\sigma_{3}$ enhances the effect of surface features in the Epolarization mode. 
6) The phase $(\phi)$ seems to show much less screening with an increase in $\sigma_{3}$, and hence the deeper fault at $\mathrm{F}_{2}$ is clearly seen at $\sigma_{3}=0.01 \mathrm{~S} / \mathrm{m}$. For the Bpolarization mode, this behaviour is further accentuated.

7) The manifestation of surface topography in the $E_{x}$ component increases with an increase of basement conductivity.

8) In profile II $\left(\mathrm{BB}^{\prime}\right)$, the highly conducting surface layer of alluvium substantially modifies the response for $T<0.1 \mathrm{sec}$.

It should, however, be noted that the model presented above may be restricted, as i) the surface and buried structures may in reality be 3-dimensional, and ii) the faults might be filled with a material whose electrical properties are drastically different from those of the material on either side.

The authors are indebted to Dr. Wannamaker for his help with regard to the algorithm. We sincerely thank Prof. V. K. Gaur, Director NGRI for his kind encouragement and help in carrying out this study. Thanks are due to Mr. Kranthi Kumar for tracing the figures and to Mrs. Lakshmi Janakiraman for typing the manuscript.

We also wish to express our gratitude to the two referees and the editor for their suggestions, which helped us significantly in improving the manuscript.

\section{REFERENCES}

Alvarez, W., Toward a theory of impact crises, EOS, 67, 649, 653-655, 658, 1986.

BAKSHI, A. K., Critical evaluation of the age of the Deccan Traps, India: Implications for flood basalt volcanism and faunal extinctions, Geology, 15, 147-150, 1987.

Clark, S. P., Handbook of Physical Constants, 562 pp., The Geological Society of America, Inc., 1966.

Courtillot, V., J. Besse, D. Vandamme, R. Montigny, J.-J. Jaeger, and H. Cappetta, Deccan flood basalts at the Cretaceous/Tertiary boundary?, Earth Planet. Sci. Lett., 80, 361-374, 1986.

Deshmukn, S. S., Volcanological and petrological appraisal of Deccan basalts, Gondwana Geological Society, Sci. Lecture Ser. 1, 30-56, 1982.

Hartnady, C. J. H., Catastrophes in the geological record: Some news, Geobulletin, 30, 36-37, 1987.

ILKISIK, O. M. and A. G. JONES, Statistical evaluation of MT and AMT methods applied to a basalt covered area in Southeastern Anatolia, Turkey, Geophys. Prospect., 32, 706-724, 1984.

Iyer, H. M., V. K. Gaur, C. V. Ramakrishna Rao, S. S. Rai, D. S. Ramesh, D. Srinagesh, and K. SuryapraKasam, A deep structure of the Deccan Traps, India, using Teleseismic P-wave residuals, Abstract, EOS, 67, 1103, 1986.

Jones, A. G., The problem of current channelling: A critical review, Geophys. Surv., 6, 79-122, 1983.

Jones, A. G., MT and reflection: An essential combination, Geophys. J. R. Astr. Soc., 89, 7-18, 1987.

KAILA, K. L., Tectonic framework of Narmada-Son lineament-A continental rift system in Central India from Deep Seismic Sounding, Geodyn. Ser., 13, 133-150, 1986.

Kaila, K. L., H. C. Tewari, and V. G. Krishna, An indirect seismic method for determining the thickness of a low velocity layer underlying a high velocity layer, Geophysics, 46, 1003-1008, 1981.

Krishna Brahmam, N. and J. G. Negi, Rift valleys beneath Deccan traps (India), Geophys. Res. Bull., 11, 207-237, 1973.

Mahoney, J. J., Deccan traps, in Continental Flood Basalts, edited by J. D. Macdougall, pp. 151-194, Kluwer Academic Publ., Hingham Mass., 1988.

Ravi Shanker, Heat-flow map of India and discussion on its geological and economic significance, Indian Miner., 42, 89-110, 1988.

Srivastava, B. J. and S. N. Prasad, Geomagnetic induction anomalies in India in relation to geology, Geophys. Surv., 5, 193-212, 1982. 
Subrahmanyam, B., Gravity and deep electrical resistivity studies for coal exploration in Deccan Basalts, Geophys. Res. Bull., 25, 142-151, 1987.

VozofF, K., The magnetotelluric method in exploration of sedimentary basins, Geophysics, 37, 98-141, 1972.

VOzOFF, K., Model study for the proposed magnetotelluric (MT) traverse in North India, Tectonophysics, 105, 399-411, 1984.

Wannamaker, P. E., J. A. Stodt, and L. Rijo, PW2D-Finite element program for solution of magnetotelluric response of two-dimensional earth resistivity structure, 71 pp., Program documentation: University of Utah Research Institute Report ESL-158, 1985.

Wannamaker, P. E., J. A. Stodt, and L. Rijo, A stable finite element solution for two-dimensional magnetotelluric modelling, Geophys. J. Roy. Astr. Soc., 88, 277-296, 1987. 